\title{
Antiarrhythmic therapy - the paradigm shifts in 2012: will it be enough to result in improved health care policies?
}

\author{
S. Saksena
}

Published online: 15 January 2013

(C) Springer Science+Business Media New York 2013

2012 proved to be a watershed year for practice guidelines and health care policy pertaining to antiarrhythmic therapy in the USA. While some antiarrhythmic therapies were directly impacted, behind the scenes, a major paradigm shift was being enacted that could affect all forms of arrhythmia management. In January 2012, I argued that we needed this paradigm shift [1]. In that commentary, the rationale was simply stated as "the implications of looking away from highly visible patterns of behavior in clinical outcomes has enormous implications for both patients subjected to unnecessary care, and wasted resources in a resource-limited global health care environment." In 2012, in a major shift in practice guidelines for cardiac resynchronization therapy, the class 1 recommendation was modified to reflect the subgroup with the overwhelming benefit from this therapy, namely left bundle branch block with a duration of $150 \mathrm{~ms}$ or greater in the patients that were candidates for this therapy for refractory heart failure [2]. A similar process occurred in limiting the expansion of the indication to class II refractory heart failure, despite the pivotal clinical trial including both class 1 and 2 patients [3].

In another important trend, the language of two class IIa guidelines was modified and sharpened to bring the focus on the specific indication for CRT. This bodes well for the future and some forms of antiarrhythmic therapy could derive immediate benefit and avoid health policy pushback. A case in point is the recent "Consensus statement on catheter ablation" from three major international societies and endorsed by three other cardiology and cardiac surgical

\section{S. Saksena $(\bowtie)$}

UMDNJ-Robert Wood Johnson School of Medicine,

161 Washington Valley Road, Suite 201,

Warren, NJ 07059, USA

e-mail: CMENJ@aol.com societies [4]. This is an example of interventional antiarrhythmic therapy that could benefit with better definition. The extraordinarily broad strokes of class 1 indications based on "symptomatic AF" inherently suggest that such an action would improve patient selection and health care resource allocation. In tacit recognition of this need, the task force behind the statement commented that in "a population of patients undergoing AF ablation, additional detail should be provided." In particular, they make mention of the category of persistent AF, its duration, and prior therapy. Perhaps of greater importance is the need for definition of comorbidities, definition of structural heart disease and its progression, and risks specific to the intervention in $\mathrm{AF}$ subpopulations such as advancing age-related complications and functional status or life expectancy. These have been critical to improvement in device guidelines and would offer value in monitoring quality, safety, and resource utilization.

In a resource-limited environment where budget neutrality is a reality, recent developments in reducing reimbursement for catheter ablation procedures for 2013 could negatively impact a valuable therapeutic clinical procedure. For those with longer term memory, the early restrictions in third party reimbursement for prophylactic ICD therapy in patients without left bundle branch block come to mind. We still struggle to define the best populations for this antiarrhythmic therapy. In 2013, we will have across the board reductions in financial support for ablation procedures in the revaluation done by the Center for Medicare Services. While this is technically done as a function of actual physician work and practice expense, it is indirectly a volumesensitive outcome. It would seem that better health care reimbursement policy for catheter ablation can be developed with clearly defined and well-supported catheter ablation practice guidelines that define the specific populations and include not only indications but also contraindications or 
other restrictions in important measure. Otherwise, this will, in my view, impact access to care for optimal subpopulations for the procedure and delay both clinical benefit and cost-effective medical care. Of equal concern in the long term are increasingly stringent restrictions on innovation and costs of developing new therapies as well as the impact of new financial taxation on the medical device industry. At the Journal, we need to continue focusing on these essential issues that are the life blood of medical advances. In 2013, we need to continue to battle for sound and fair health care policy in which all those who contribute to better care of patients are given an opportunity to thrive and succeed.

In 2012, the Journal looked back and celebrated its 15th anniversary at its annual meeting. We remembered the contributions of the founding associate editors and recognized the contributions of our existing leadership. We are now a truly international journal in scope and participation. We have achieved new objectives and continue to grow in manuscript submission, worldwide interactions, and new sections in the journal. As 2013 opens, we have new goals and an expanded mission. In 2013, the journal will provide a forum for health care policy pertaining to our field. I am particularly concerned that this area is being increasingly relegated to advocacy sections in professional societies and that grass roots discussion in open fora is limited. The next entire issue of this journal will be an inaugural health policy issue highlighting these concerns. Drs. Hlatky, Turakhia, and Reynolds will guest edit this issue. In future issues, we will invite manuscript submission in areas of health care policy as a regular feature in the journal and would promote discussion and comment on these issues on our Facebook journal page.

Finally, this annual commentary would not be complete without recognizing the outstanding support of our editorial leadership, board members, and the staff at the journal. Their contributions are the cornerstone of our success and I thank them all for their outstanding efforts.

\section{References}

1. Saksena, S. (2012). Clinical trials of antiarrhythmic therapies and optimizing health care resource deployment: the need for a paradigm shift. Journal of Interventional Cardiac Electrophysiology, $33,1-3$.

2. Tracy, C. M., Epstein, A. E., Darbar, D., et al. (2012). 2012 ACCF/ AHA/HRS focused update of the 2008 guidelines for device-based therapy of cardiac rhythm abnormalities: a report of the American College of Cardiology Foundation/American Heart Association Task Force on Practice Guidelines. Journal of the American College of Cardiology, 60, 1297-1313.

3. Moss, A. J., Hall, W. J., Cannom, D. S., et al. (2009). Cardiacresynchronization therapy for the prevention of heart-failure events. The New England Journal of Medicine, 361, 1329-1338.

4. Calkins, H., Brugada, J., Packer, D. L., et al. (2012). HRS/EHRA/ ECAS expert consensus statement on catheter and surgical ablation of atrial fibrillation: recommendations for personnel, policy, procedures and follow-up. Journal of Interventional Cardiac Electrophysiology, 33, 171-257. 